\title{
A Study on Cross-Cultural Adaptation of Mainland Chinese Students in Taiwan from the Perspective of Self-Identity
}

\author{
Email address: \\ 584165097@qq.com (Li Zhiwei) \\ ${ }^{*}$ Corresponding author
}

Shen Chingcheng, Chang Teyi, Li Zhiwei*

Institute of Tourism Management, National Kaohsiung University of Hospitality and Tourism, Kaohsiung, Taiwan

To cite this article:

Shen Chingcheng, Chang Teyi, Li Zhiwei. A Study on Cross-Cultural Adaptation of Mainland Chinese Students in Taiwan from the Perspective of Self-Identity. Humanities and Social Sciences. Vol. 6, No. 1, 2018, pp. 30-37. doi: 10.11648/j.hss.20180601.15

Received: March 23, 2018; Accepted: April 16, 2018; Published: May 11, 2018

\begin{abstract}
At present, there are a total of 9462 mainland Chinese students with formal degrees in Taiwan. There are a large number of mainland students studying in Taiwan, but there are few studies on their adaptation to life and learning in Taiwan. This study takes the view of self-identity, to explore the cross-cultural adaptation of mainland students in Taiwan, this study conducted in-depth interviews with 7 mainland students from the National Kaohsiung University of Hospitality and Tourism by means of qualitative research and literature Review. The factors of cross-cultural adaptation divided into life adaptation, cultural adaptation, learning adaptation, interactive adaptation and leisure adaptation. A total of 204 valid questionnaires were received, and structural equation model analysis was carried out with SPSS22 and LISREL852. The results showed that the view of self-identity could be divided into value identity, social identity, group identity and personality identity, the value identity point of view is the most important. Secondly, self-identity view has positive and significant effects on life adaptation, cultural adaptation, learning adaptation, interactive adaptation and leisure adaptation. Self-identity view can be divided into high self-identity group, middle self-identity group and low self-identity group, while high self-identity view has high cross-cultural adaptation. Finally, in life adaptation, mainland students are more concerned with the consumption environment, medical care and entertainment, transportation and related living facilities; in learning adaptation, mainland student pays more attention to language and writing; in interactive adaptation, mainland student pays more attention to the interaction of administrative personnel. This study puts forward relevant suggestions, hoping to arouse the attention of Taiwan authorities and enrollment schools, achieve convergence management, and also hope to provide reference and reference for the vast number of mainland students to apply for study in Taiwan.
\end{abstract}

Keywords: Mainland Chinese Students, Cross-Cultural Adaptation, Self-Identity

\section{Introduction}

The Chinese mainland and Taiwan come down in one continuous line. Because of historical reasons and political factors, both sides face restrictions in political, economic, social and cultural exchanges, so that cross-strait exchanges of higher education was once in a state of stagnation [1]. In September of 2011, Chinese mainland students (hereinafter referred to as mainland students) were officially launched to study for degrees in Taiwan. According to statistics from the Mainland Student Joint Recruitment Committee, there were 9,462 students with degrees in Taiwan as of December of 2017, and the overall enrollment situation was not as expected. In fact, the China mainland is already the world's largest source of international students.

The mainland is geographically close to Taiwan, and opening up mainland students to study in Taiwan is conducive to developing Taiwan's higher education market and alleviating the imbalance between supply and demand caused by declining fertility rate [2]. However, the mainland students are different from those of Taiwanese in language, culture and living habits. They have to face all kinds of problems and difficulties in life adaptation while they are studying. How to solve the problems and whether they have appropriate support and assistance are worthy of attention. Identity is the inner nature of the individual, which is self-perception formed by the interaction with the sociocultural context [3]. It is worth 
discussing whether the mainland students will extend their identity to Taiwan because of their own internalization, identify with themselves and society. The process that people who produce cultural shock, adjust their sense of physical and psychological uncertainty, is called as cross-cultural adaptation [4]. Many overseas students have difficulties in adapting to cross-cultural conditions, which affects their studies and daily life, and even causes adverse events [5]. So, the cross-cultural adaptation situation of the mainland students in Taiwan is the main problem to be discussed in this study.

According to the above research motivation, the purpose of this study is: to understand the mainland students' self-identity in Taiwan; to understand the cross-cultural adaptation situation of the mainland students in Taiwan; to understand the main factors that affect the cross-cultural adaptation of mainland students. According to the findings and conclusions of the study, concrete and feasible recommendations are expected to be raised for the vast number of mainland students, school administration and practice field.

\section{Literature Review}

\subsection{Self-Identity}

Self-identity is established through mutual influence among the politics, history and culture. According to Huang hou-ming [6], self-identity refers to all past, present and future narratives related to the individual. Huang rui-qi regards self-identity as a part of self-exploration, self-establishment or self-change by combining with the reflection process of personal change and social change in the context of modern society [7]. Ribbe believes that young people must be given the necessary support and encouragement to help them complete their self-identification process [8]. Chickering and Reisser divides self-identity into: 1. Personal identity: to understand or accept the individual's unique and true inner self-psychological tendency by means of the individual's role, occupation, trait, etc; 2. Social identity: It is the interaction, learning and reciprocal relationship among oneself and others and environment, which is influenced by individual self-consciousness and social role; 3. Collective identity: Influenced by the expectations and norms of others or groups [9].

Ashforth and Mael thinks that social identity is an individual identity with a certain social group, and defines the relationship between it and the group of identity by self-concept [10]. Specifically, people classify themselves into various social categories to help them enter the social environment to which they belong. The purport of social identity theory is to discuss the relative relationship between individual and group, the relationship between groups, the meaning of relationship and the external behavior. These relationships may be innate, such as gender or ethnicity, or may be acquired, such as occupation and identity [11].

Liao hsiao-wen and Chen ching-lin used 114 young people of research, the study showed that there was a clear correlation between self-identity and psychological well-being [12]. Huang, chin-yun use students from technology university of south Taiwan, once again explored that determined personal commitments, increased self-identity, can promote positive positive psychological well-being of young people [13]. This study try to explores the cross-cultural adaptation in mainland China students using self-identity theory.

\subsection{Cross-Cultural Adaptation}

Black thinks that cross-cultural adaptation is the psychological adjustment when individuals are in different environments in the face of cross-cultural shocks [14]. Black and Grefersen proposed that cross-cultural adaptation is the degree of psychological adaptation and familiarity with the culture of the host country in different cultural life and work adaptation [15]. Kim defines cross-cultural adaptation as a continuous or consecutive dynamic process in which individuals interact with a completely new, unfamiliar or changing cultural environment to re-establish and maintain a relatively stable, mutually beneficial and useful relationship with this environment [16]. As such, cross cultural adaptation is defined as a dynamic process owing to individuals' constant interaction with their environment in this theory [17] In facing challenges, dynamic human nature struggles for an internal balance through acquiring new cultural communication practices, participating actively in the interpersonal and mass communication processes of the local community and being competent in host communication system. Every individual possesses a field and since individuals have a lot of differences, their fields are different from each other. As individuals gain more information and knowledge about the environment, their field changes to accommodate them [18]. In 2007, the American Psychological Society defined intercultural adaptation as: Regulate another culture in terms of attitude and behavior, usually taking on various levels of appearance in degree or type [19].

Black and Stephens divided cross-cultural adaptation into general adjustment, interaction adjustment, and work adjustment [20]. Lin ming-hung divided cross-cultural adaptation into psychological adaptation, job adaptation, life adaptation, and cultural adaptation [21]. Ding mei-li cross-cultural fo Thai student abroad in Taiwan, divided cross-cultural adaptation into general adjustment, learning adjustment and interaction adjustment [22]. Peng chung-chen divided cross-cultural adaptation into general adjustment, interaction adjustment and cultural adjustment [23]. Chen bing-song [24], Xu bo-han [25], Huang yu-lan [26] both of them have study on the cross-cultural adaptation of intenational students in Taiwan.

\subsection{Mainland Student Related Research}

The mainland students refers to the students study in Taiwan who have the nationality of the people's Republic of China. The mainland students are generally divided into two types, one is short-term exchange students with the duration of 
generally 6-12 months; One is formal students with formal qualifications to study in Taiwan for a two-year bachelor's degree, a university, a master's degree, and a doctorate. This study selects the formal degree students as the research object, who need to stay in Taiwan for a few years, so the cross-cultural adaptation of the mainland students is of great value and significance.

Han yi-juan focuses on the motivation of studying and life adaptation of the exchange students in Taiwan. The result of questionnaire analysis shows that the higher the motivation for studying is, the better the adaptation to life is. The main pressure of their life in Taiwan comes from their academic performance [27]. Lin chia-Cheng takes exchange students from I-Shou University and Taiwan University as the research subjects, Who believe that Taiwan residents have a negative stereotype of the mainland people, and to some extent discriminate against the mainland students who come to Taiwan to study [28]. Hu shao-chia analyzes the mainland students' self-identity transformation and their cross-cultural adaptation experience in Taiwan by means of narrative analysis. Due to the difference between the mainland students and Taiwan students in social culture and identity, the mainland students experienced the disharmony of identity in Taiwan, resulting in his reflection on the culture of his home country and the reconstruction of his personal identity and career planning [29]. Zhang bao-rong, Liu guo-jun, Xiao ri-kui, Wang zhen-wei and Wu le-yang point out that the longer the mainland students live in Taiwan, the deeper they feel about Taiwan's society, economy, culture, and education [30]. Huang li-hong and Wu qiu-qin use push-pull theory and empirical research method to prove that push-pull factors have significant correlation with learning satisfaction [31]. Lin xian-ming and Song yu-xian discuss the life adaptation of the mainland students in Taiwan and their interaction with their peers [32]. The result shows that the mainland students adapt to life in Taiwan well, and there is no hindrance in their interaction with the students in Taiwan. However, as a result of policy constraints, the mainland students are prone to have an imbalance sense in daily life and rights and interests. This study find that the current research topics of cross-strait scholars focus on political, economic, cultural and ideological studies, and lack of cross-cultural adaptation to the situation of self-identity of the mainland students.

\section{Method}

\subsection{Research Setting}

In order to show the status of self-identity and cross-cultural adaptation of mainland students in Taiwan, this study adopts qualitative research combined with quantitative research method. First of all, through the method of purposive sampling, this study selects seven mainland students from National Kaohsiung University of Hospitality and Tourism as the research samples for in-depth interviews, wherein, 5 are still studying and 2 have temporary absence from school. The sample size is consistent with the selection of qualitative research interviews. All the interviews are transcribed into verbatim transcripts, and the contents are confirmed with the interviewees. After the correction, the data are analyzed by taking root theory to establish the dimension scale of the mainland students' self-identity and cross-cultural adaptation scale. Then the questionnaire and statistical analysis are carried out. As shown in Table 1:

Table 1. The basic situation of the interviewee.

\begin{tabular}{lllll}
\hline No. & Gender & Age & Origin & Student status \\
\hline A & male & 28 & Fujian & Master \\
B & male & 22 & Fujian & Undergraduate \\
C & female & 21 & Guangdong & Undergraduate \\
D & female & 21 & Liaoning & Undergraduate \\
E & female & 24 & Guangdong & Undergraduate \\
F & female & 21 & Guangdong & Undergraduate \\
G & male & 24 & Guangdong & Undergraduate \\
\hline
\end{tabular}

\subsection{Research Hypothesis}

Based on relevant literature and interview data, this study proposes hypotheses as follows.

H1: Mainland student self-identity has positive influences on life adaptation.

H2: Mainland student self-identity has positive influences on cultural adaptation.

H3: Mainland student self-identity has positive influences on learning adaptation.

H4: Mainland student self-identity has positive influences on interactional adaptation.

H5: Mainland student self-identity has positive influences on leisure adaptation.

\subsection{Sample Collection}

This study mainly investigates the formal degree mainland students, with the purposive sampling method, distributes network questionnaire in the virtual community such as QQ community of the Mainland Student Joint Recruitment Committee, WeChat Exchange Group of provincial Mainland Student Joint Committee, and so on. A total of 204 valid questionnaires are collected. With SPSS22 and LISREL852 for Descriptive Statistics, Factor analysis, Reliability analysis Validity analysis, and Structural equation model analysis. Questionnaires were using Likert's five-point scale, with 1 being Strongly disagree, 2 being disagree, 3 being ordinary, 4 being agree, and 5 being Strongly agree. 


\section{Results}

\subsection{Mainland Student Demographics}

Most of the respondents are female (56.4\%) mostly aging from 20 to $29(80.9 \%)$, according with the young group of the mainland students to study, which is also the main group to promote cross-strait exchanges in the future; besides, they are featured with the following characteristics: marital statuses of mostly being unmarried (94.6\%); Bachelor's degree (44.6\%) in Taiwan; Their school area of mainly being in the north $(47.1 \%)$, centering on the national university $(52.9 \%)$, and belonging to comprehensive university $(61.8 \%)$; living in Guangdong Province (26.5\%) mostly, followed by Fujian Province $(21.1 \%)$. In view of study motivation, having further education $(76 \%)$ is most important, followed by the experience of exotic customs (49\%), it can be seen that the having further education, at the same time, experiencing exotic customs, is the main reason for the mainland students to study in Taiwan; the main source of information for the mainland students to study in Taiwan is web search (32.4\%).

\subsection{Factor Analysis Results}

With principle component analysis extract the common factors, calculate the common interpretation variance of all measured variables, and transform the mode through the Varimax method, for the values with the commonality greater than 0.40 and factor loading greater than 0.50 , they are considered to be significant. Therefore, delete the non-conforming items, the factor analysis result is as shown in Table 2. This study conducts reliability analysis on factor facets based on Cronbach's $\alpha$ coefficient, and the coefficients of each surface are more than 0.5 , which shows the all items of the facet have good consistency.

Table 2. Factor analysis results.

\begin{tabular}{|c|c|c|c|c|}
\hline Items & Mean & SD & Factor loading & Cronbach's $\alpha$ value \\
\hline Self-identity & & & & 0.70 \\
\hline I'm a well-prepared person to act. & 3.66 & 0.85 & 0.79 & 0.84 \\
\hline I'm used to solving my own problems. & 3.91 & 0.92 & 0.79 & \\
\hline I have my own values. & 4.15 & 0.97 & 0.78 & \\
\hline I'm very independent. & 3.84 & 0.92 & 0.72 & \\
\hline I change the stereotype of the mainland in Taiwan & 3.41 & 0.90 & 0.57 & \\
\hline I agree with the taiwanese & 2.78 & 0.68 & 0.82 & 0.65 \\
\hline Taiwanese are generally friendly, hospitable and respectful & 3.50 & 0.86 & 0.65 & \\
\hline When I go to a strange place, I feel anxious. & 2.73 & 0.95 & 0.84 & 0.57 \\
\hline I don't know how to socialize with my Taiwanese classmates. & 2.56 & 1.00 & 0.75 & \\
\hline I like to make friends and be outgoing & 3.57 & 0.87 & 0.81 & 0.57 \\
\hline I'm a friendly, easy-going person. & 4.02 & 0.91 & 0.63 & \\
\hline Life adaptation & & & & 0.81 \\
\hline Improvement of related living facilities near the school & 3.16 & 1.11 & 0.77 & 0.76 \\
\hline Public transport facilities & 2.81 & 1.12 & 0.67 & \\
\hline Good entertainment facilities & 3.15 & 0.86 & 0.61 & \\
\hline A variety of night market snacks & 3.28 & 1.08 & 0.86 & \\
\hline Good dietary adaptation & 3.30 & 1.04 & 0.83 & \\
\hline Good living environment & 3.45 & 0.96 & 0.62 & \\
\hline Reasonable consumption and price of commodity & 3.01 & 0.87 & 0.85 & 0.56 \\
\hline Good shopping environment & 3.47 & 0.86 & 0.72 & \\
\hline cultural adaptation & & & & 0.57 \\
\hline I will study Taiwanese culture & 3.59 & 0.86 & 0.90 & 0.74 \\
\hline I am adapted to the local conditions in Taiwan & 3.51 & 0.79 & 0.82 & \\
\hline I want to increase my sense of belonging to Taiwan & 3.06 & 0.96 & 0.64 & \\
\hline Don't care about Taiwan's political transfer & 2.74 & 1.00 & 0.91 & 0.79 \\
\hline Don't normally care about changes in Taiwan's public policy & 2.71 & 0.94 & 0.90 & \\
\hline learning adaptation & & & & 0.74 \\
\hline Adapt well in class with students & 3.50 & 0.87 & 0.83 & 0.78 \\
\hline Well adapted to teaching methods of the teachers & 3.60 & 0.86 & 0.79 & \\
\hline A more perfect scholarship system & 2.75 & 1.07 & 0.83 & 0.69 \\
\hline Schools will arrange internship and employment opportunities for the mainland students & 2.44 & 1.05 & 0.81 & \\
\hline The school has a special service institution for mainland students & 3.55 & 1.12 & 0.69 & \\
\hline There are basically no barriers in language. & 4.05 & 0.89 & 0.87 & 0.74 \\
\hline Traditional Chinese characters are basically unhindered & 4.16 & 0.89 & 0.70 & \\
\hline interactional adaptation & & & & 0.81 \\
\hline Students interact well with each other & 3.60 & 0.86 & 0.89 & 0.85 \\
\hline Teachers interact well with each other & 3.75 & 0.80 & 0.82 & \\
\hline Good interaction with the surrounding people & 3.48 & 0.83 & 0.81 & \\
\hline Schools treat mainland students equally & 3.21 & 1.10 & 0.83 & 0.67 \\
\hline
\end{tabular}




\begin{tabular}{|c|c|c|c|c|}
\hline Items & Mean & SD & Factor loading & Cronbach's $\alpha$ value \\
\hline Administrative staff interact well with each other & 3.51 & 0.87 & 0.70 & \\
\hline Class tutors will care actively about their study life & 3.40 & 1.06 & 0.69 & \\
\hline leisure adaptation & & & & 0.89 \\
\hline In order to get to know more about Taiwan & 3.59 & 0.94 & 0.90 & 0.92 \\
\hline Taiwan is rich in tourism resources & 3.50 & 0.92 & 0.90 & \\
\hline To expand knowledge & 3.42 & 0.93 & 0.87 & \\
\hline To challenge myself & 3.31 & 0.94 & 0.79 & \\
\hline Taiwan's tourism consumption is low & 2.91 & 0.86 & 0.85 & 0.51 \\
\hline Convenient public transport in Taiwan & 3.02 & 1.02 & 0.72 & \\
\hline
\end{tabular}

\subsection{Cluster Analysis and ANOVA Analysis}

This study takes value identity (VI), social identity (SI), group identity (GI) and personal identity (PI) as the segmentation variables to conduct cluster analysis on the self-identity views, as is shown in Table 3. Divide the mainland students into three groups, the first group's value identity, social identity, group identity and personal identity are all very high, so name it as high self-identity behavior group (HIBG); the second group's value identity, social identity, group identity and personal identity are intermediate, so name it as middle self-identity behavior group (MIBG); the third group's value identity, social identity, group identity and personal identity are all very low, so name it as low self-identity behavior group (LIBG).

In Table 4, it can be seen that there are significant differences in life adaptation, cultural adaptation, learning adaptation, interactive adaptation and leisure adaptation of the mainland students with different segmentation variables. Adopt scheffe comparison method to conduct Tukey Test, in order to understand the order of the average value among different groups. The result of multiple comparison shows that there is no significant difference in the adaptation of living environment and political feeling of the mainland students, but there are obvious differences in other Variables. It can be seen that the mainland students with high self-identity behaviors have high life adaptation, high cultural adaptation, high learning adaptation, high interactive adaptation and high leisure adaptation.

Table 3. Self-identity Cluster analysis results.

\begin{tabular}{lllllll}
\hline No. & HIBG $\mathbf{n}=\mathbf{1 0 0}$ & MIBG $\mathbf{n = 9 2}$ & LIBG $\mathbf{n = 1 2}$ & F-value & P-value & Scheffe \\
\hline VI & 4.13 & 3.69 & 1.82 & $135.27^{* * *}$ & 0.000 & $(1,2,3)$ \\
SI & 3.29 & 2.93 & 2.56 & $15.89^{* * *}$ & 0.000 & $(1,2,3)$ \\
GI & 2.05 & 3.23 & 3.13 & $108.25^{* * *}$ & 0.000 & $(1,2,3)$ \\
PI & 4.18 & 3.63 & 1.92 & $103.16^{* * *}$ & 0.000 & $(1,2,3)$ \\
\hline
\end{tabular}

Table 4. Cross-culturl adaptation ANOVA analysis results.

\begin{tabular}{|c|c|c|c|c|}
\hline Variable & Factor & F-value & P-value & Scheffe \\
\hline \multirow{3}{*}{ life adaptation } & Living environment & 2.69 & 0.070 & $(1=2=3)$ \\
\hline & Food environment & $16.13 * * *$ & 0.000 & $(1,2,3)$ \\
\hline & Consumption environment & $20.84 * * *$ & 0.000 & $(1=2,3)$ \\
\hline \multirow{2}{*}{ cultural adaptation } & Political experience & 0.60 & 0.549 & $(1=2,3)$ \\
\hline & Cultural attribution & $56.92 * * *$ & 0.000 & $(1,2,3)$ \\
\hline \multirow[b]{2}{*}{ learning adaptation } & Classroom adaptation & $35.52 * * *$ & 0.000 & $(1,2,3)$ \\
\hline & Assisted support & $5.77 * * *$ & 0.000 & $(1,2,3)$ \\
\hline \multirow{2}{*}{ interactive adaptation } & Human interaction & $30.15 * * *$ & 0.000 & $(1,2,3)$ \\
\hline & Administrative interaction & $4.68 *$ & 0.010 & $(1,2,3)$ \\
\hline \multirow{2}{*}{ leisure adaptation } & Taiwanese knowledge & $9.32 * * *$ & 0.000 & $(1,2,3)$ \\
\hline & Leisure costs & $5.14 * *$ & 0.007 & $(1=2,3)$ \\
\hline
\end{tabular}

$* \mathrm{p}<0.05$

\subsection{Structural Model}

This study verifies the hypothesis model by aid of the structural equation model and inspects the causality between the potential variables. The structural equation model result is as shown in Table 5, all indicators of the overall structural model are suitable and in line with the criteria $\left(x^{2}=185.03\right.$, $\mathrm{df}=95.03, \mathrm{x}^{2} / \mathrm{df}=1.95, \mathrm{RMSEA}=0.072, \mathrm{CFI}=0.97, \mathrm{IFI}=0.97$, $\mathrm{GFI}=0.90$, AGFI $=0.85, \mathrm{NFI}=0.94$, NNFI $=0.96$ ), indicating that the model and empirical data are suitable for each other.
The result shows that all the hypothesis are valid, and self-identity positively affects life adaptation $\left(r^{2}=0.89\right)$, so $\mathrm{H} 1$ is supported; self-identity positively affects cultural adaptation $\left(r^{2}=0.70\right)$, so $\mathrm{H} 2$ is supported; self-identity positively affects learning adaptation $\left(r^{2}=0.95\right)$, so $\mathrm{H} 3$ is supported; self-identity positively affects interactive adaptation $\left(r^{2}=0.93\right)$, so $\mathrm{H} 4$ is supported; self-identity positively affects leisure adaptation $\left(r^{2}=0.60\right)$, so $\mathrm{H} 5$ is supported. As shown in Figure 1: 


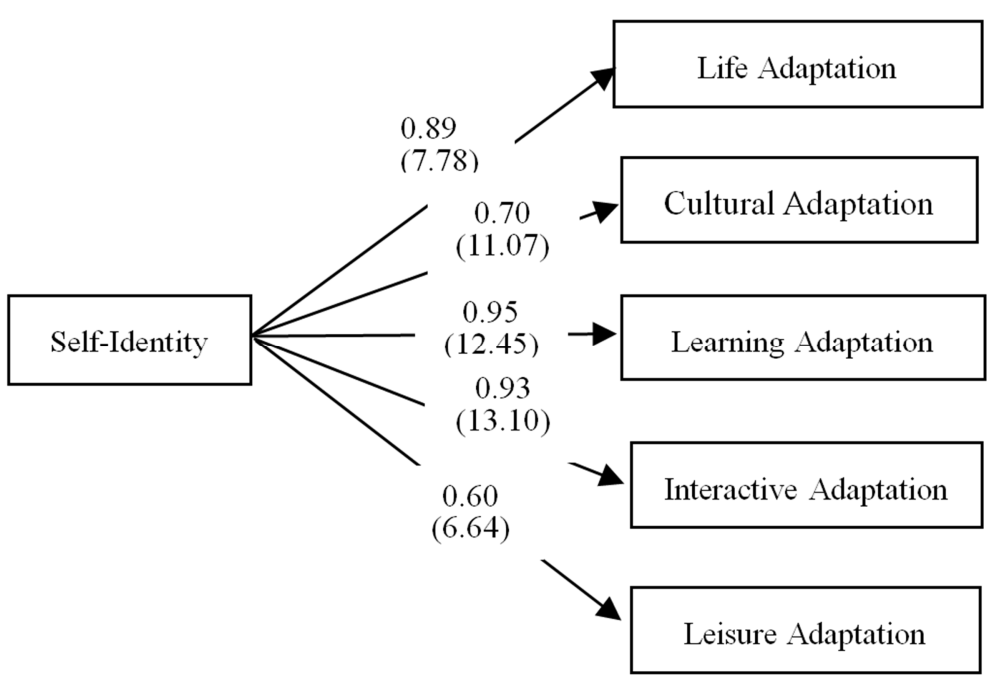

Figure 1. Structural model figure.

\section{Conclusion}

\subsection{Discuss}

In the cognitive analysis on self-identity of the mainland students, the students with higher scores are those who have their own values, they are very independent persons and get used to solving their own problems. It can be seen that the mainland students have strong independent consciousness and independent values, while in the analysis on the social identity of Taiwan and Taiwan students' group identity, the scores are very low.

In the cross-cultural adaptation of the mainland students, life adaptation, cultural adaptation, learning adaptation, interactive adaptation and leisure adaptation no so good. In terms of life adaptation, the mainland students generally can not adapt to the diet of Taiwan, they think that Taiwan's public transport is inconvenient, Taiwan's price of commosity is relatively high; In terms of cultural adaptation, the mainland students are also willing to increase his understanding of Taiwan's culture. However, Taiwan's media often create stereotypical impressions of the mainland, coupled with the influence of Taiwan's political factors, so there are obstacles to cultural adaptation. In terms of learning adaptation, because of the same root origin, the mainland students are well adapted to language and writing but they have lower cognitive value in teacher teaching, mutual help among classmates, internships and employment, scholarships, and so on. The mainland students enrollment schools generally do not have special agency to support the study of mainland students, therefore, the mainland students in Taiwan have a lower degree of satisfaction on learning adaptation. In terms of interactive adaptation, the school has different treatment towards the mainland students, teachers and administrators do not treat them equally, the class mentors generally do not care about their study life, and the interaction situation of students is poor. In terms of leisure adaptation, the mainland students generally think that Taiwan's public transportation is not convenient enough, and Taiwan's consumption level is high, which hinder the leisure adaptation. The results show that there is a strong correlation between the self-identity of the mainland students and their cross-cultural adaptation in Taiwan.

\subsection{Management Implications}

The mainland students' identity with Taiwan and their cross-cultural adaptation in Taiwan are poor. The key lies in the loosening of policy and law. The Taiwan government and the competent education authorities should actively open up policies and regulations such as social security, medical care and health care for mainland students, especially the lifting of the ban on the policy of "three restrictions and six noes", so as to truly support the mainland students' study and life in Taiwan from a policy perspective and solve their worries in study. The mainland student enrollment schools, especially private universities with large enrollment numbers, should set up a special Mainland Student Management Office, strengthen the functions of the international affairs service for mainland students, provide special support staff for the mainland students, and actively integrate with other mainland student alliances thus to put concern for the mainland students into practice. Teachers should promote teaching professionalism, administrative staff should enhance service attitude to treat the mainland students equally. At the same time, the school should actively improve the surrounding traffic, enhance the related life facilities, so that the students in Taiwan have a strong sense of belonging. And the vast number of students in Taiwan, as well as those who are about to apply to study in Taiwan, should correct study and life attitude, adopt a positive attitude, strengthen the sense of self-identity, and cultivate the ability of social communication. Only by learning more about the political, historical and cultural context of Taiwan and actively integrating into Taiwan's life and culture can we enhance the adaptability of life in Taiwan and contribute to the successful completion of our studies.

\subsection{Limitations and Suggest}

This study adopts the online questionnaire and aims only at 
the formal degree mainland students, so the sample size is relatively small. In addition, this study selects most of the students in the north and south of the university with few students in the east and the outlying island, so the samples are not completely representative. The future study will expand the sample to conduct step sampling on the mainland students of the schools in the north, central part, south, east and outlying islands, covering the entire Taiwan, so that the sample will more representative. The future study will also attempt to compare the cross-Taiwan adaptation of mainland students with cross-mainland adaptation of Taiwan students in order to find out the differences in cross-strait learning among students from both sides.

\section{References}

[1] Li, Z.-W. (2016). A study of National Kaohsiung University of Hospitality and Tourism mainland chinese student. Paper presented at the meeting of the 8th Asia Pacific Alliance on Tourism and Hospitality Education \& The 16th Annual Conference in Hospitality \& Tourism. Kaohsiung: National Kaohsiung University of Hospitality and Tourism tourism College.

[2] Wu, Z.-D., \& Tang, J.-W. (2009). Analysing the mainland student to Taiwan education policy from the perspective of international students' mobile trend. Journal of Education Research, 187, 75-82.

[3] Adams, G. R., \& Marshall, S. K. (1996). A developmental social psychology of identity: Understanding the person-in-context. Journal of Adolescence, 19 (5), 429-442.

[4] Liu, P.-L. (2008). The effect of cross-cultural training on cross-cultural adaptation of expatriates from Taiwan. Unpublished master thesis, National Chung Cheng University.

[5] Zhuang, R.-B. (2014). Talking about cross-cultural adaptation of Chinese Students overseas. Journal of Popular Science, l (9), 149.

[6] Huang, H.-M. (2002). The game of adventuring self-identity in the cyberspace. Journal of Education and Society Research, $2,64-106$

[7] Huang, R.-Q. (2005). Recommended order: Giddens phenomenon, Modernity and Self-identity: Late Modern Self-identity and Society. Taipei: Zuoan.

[8] Ribbe, R. (2011). Understanding the effects of adventure-based orientation programs on identity formation and the adaptation college. Unpublished doctoral thesis, Biola University.

[9] Chickering, A., \& Reisser, L. (1993). The seven vectors: An overview. Education and Identity ( $2^{\text {nd }}$ edition). Jossey-bass edition.

[10] Ashforth, B. E., \& Mael, F. (1989). Social identity theory and the organization. Journal of Academy of management review, $14(1), 20-39$.

[11] Yang, P.-S. (2009). Developing social workers group identity in small-sized elderly care homes-an application of social identity theory. Journal of Dongwu Social Work Journal, 21, 1-26.

[12] Liao, H.-W. \& Chen, C.-C. (2011). Identity Status, Self-Defining Memory and Psychological Well-Being in
Emerging Adulthood. Journal of Applied Psychological Research, 51, 79-110.

[13] Huang, C.-Y. (2015). The Study of the Relations Among Career Exploration, Self- identity Status and Psychological Well-Being of Undergraduates. Unpublished master thesis, National Pingdong University.

[14] Black, J. S. (1988). Work role transitions: A study of American expatriate managers in Japan. Journal of International Business Studies, 19, 277-294.

[15] Black, J. S., \& Gregersen, H. B. (1991). The other half of the picture: Antecedents of spouse cross-cultural adjustment. Journal of International Business Studies, 22, 461-477.

[16] Kim, Y. Y. (1988). Communication and cross-cultural adaptation: An integrative theory. Multilingual Matters.

[17] Hamad, R. \& Lee CM (2013). An assessment of how length of study-abroad programs influences cross-cultural adaptation. Journal of Human Behavior in the Social Environment, 23 (5), 661-674.

[18] Cronshaw, SF. \& McCulloch, AN. (2008). Reinstating the Lewinian vision: From force field analysis to organization field assessment. Journal of organization development, 26 (4), 89-103.

[19] Zhang. Y.-S. (2010). The research of relationship between international students' cross-cultural adjustment and cultural leisure activities participation. Unpublished master thesis, University of Li De.

[20] Black, J. S., \& Stephens, G. K. (1989). The influence of the spouse on American expatriate adjustment and intent to stay in Pacific Rim overseas assignments. Journal of management, 15 (4), 529-544.

[21] Lin. M.-H. (2002). A study of adjustment factors and indicators for the expatriates of Taiwan business. Unpublished master thesis, Chang Jung Management College.

[22] Ding, M.-L. (2009). The research on the relationships among cross-cultural adjustment, leisure involvement, leisure motivation, leisure constraint and leisure satisfy for Thai student abroad in Taiwan. Unpublished master thesis, National Kaohsiung University of Hospitality and Tourism.

[23] Peng, C.-C. (2014). A study on learning motivation, cross-cultural adjustment and learning satisfaction of international exchange students. Unpublished master thesis, Wenzao Ursuline University of Languages.

[24] Chen, B.-S. (2017). Overcoming and Adapting Different Cultures and Identity from those Students coming from China-Using the Socializing Method to Investigate the Progresses. Unpublished master thesis, University of Taipei.

[25] Xu, B.-H. (2017). Culture Shock and Cross-Cultural Adaptation of International Students in Taiwan. Unpublished master thesis, National Taiwan University of Science and Technology.

[26] Huang, Y.-L. (2017). Adapting overseas: A study of Facebook usage and cross-cultural adaptation among Malaysian Chinese students in Taiwan. Unpublished master thesis, National Chengchi University.

[27] Han, Y.-J. (2011). The learning motivation and the adjustment of students from China in Taiwan. Unpublished master thesis, National Taiwan Normal University. 
[28] Lin, C.-C. (2011). The study on mainland student's Satisfaction in exchange program in Taiwan --- the case of National Taiwan University and I-Shou University. Unpublished master thesis, National Taiwan University.

[29] Hu. S.-C. (2012). Reflections on journeying to Taiwan: A PRC student's intercultural narrative and identity reconstruction. Journal of Journalism research, 111 (4), 44-87.

[30] Zhang, B.-R., Liu, G.-J., Xiao, R.-K., Wang, Z.-W., \& Wu, Le.-Y. (2014). Research on mainland student social adaptability and satisfaction in Taiwan. Journal of Taiwan research journal, 14, 1-10.
[31] Huang, L.-H., \& Wu, Q.-Q. (2015). An empirical study of mainland student learning satisfaction at Taiwan. Journal of chongqing institute of socialism, 1, 53-57.

[32] Lin, X.-M., \& Song, Y.-X. (2015). The exploration of life adaptation and the situation of peer groups of mainland student in Taiwan. Journal of Youth Exploration, 14, 51-60. 